\title{
Twinning arrangements and service delivery in Zimbabwe's local authorities: The case of Bulawayo City Council (Zimbabwe) and eThekwini Municipality (South Africa)
}

\section{Authors: \\ Alouis Chilunjika ${ }^{1,2}$ \\ Sharon RT Chilunjika ${ }^{2}$ ] \\ Affiliations: \\ ${ }^{1}$ Department of Public \\ Management, Governance and Public Policy, Faculty of \\ Commerce, Business and Economics, University of \\ Johannesburg, Johannesburg,} South Africa

2Department of Governance and Public Management, Faculty of Social Sciences, Midlands State University, Gweru, Zimbabwe

Corresponding author: Alouis Chilunjika, chilunjika@gmail.com

\section{Dates:}

Received: 22 June 2021 Accepted: 13 Oct. 2021 Published: 30 Nov. 2021

How to cite this article: Chilunjika, A. \& Chilunjika, S.R.T., 2021, 'Twinning arrangements and service delivery in Zimbabwe's local authorities: The case of Bulawayo City Council (Zimbabwe) and eThekwini Municipality (South Africa)', Journal of Local Government Research and Innovation 2(0), a37. https://doi.org/10.4102/ jolgri.v2i0.37

\section{Copyright:}

(c) 2021. The Authors. Licensee: AOSIS. This work

is licensed under the Creative Commons Attribution License.

Read online:
The Zimbabwean local government environment has been affected by chronic defects in the provision of basic public services. As such, city twinning has been adopted as one of the strategies to address the impasse in service delivery as it allows for the sharing of expertise in local governance, development, strategic international relations and the enhancement of service delivery in local authorities. Using the exploratory case study research design the study explores the impact the twinning arrangement between Bulawayo City Council (BCC) and eThekwini Municipality and how it has enhanced service delivery in Bulawayo. Data was gathered from written documents, observations and in-depth interviews. The study established that the BCCeThekwini cooperation has been very fruitful and Bulawayo City Council has benefited immensely through the exchange of ideas and information as well as technology transfer among others from this twinning arrangement. Nonetheless, it was also observed that weak legal and financial frameworks hinders the city twinning partnership from realising its full fruition. The study concluded that city twinning between BCC and eThekwini is a favourable route for creating sustainable South to South linkages that benefit developing cities. As recommendations, the article argues that there is need for clarity in defining the partnership roles and goals, community involvement as well as an enabling policy and institutional environment.

Keywords: twinning; service delivery; local authorities; Bulawayo City Council; eThekwini Municipality.

\section{Introduction}

The concept of twinning towns and municipalities can be traced back to the 1920s; and it has continued to progress from a global tool of friendship and cultural exchange to a more complex web of business relationships and networks that provide a better framework to enhance development in local governments (Joenniemi \& Janczak 2017). Originally, twinning of cities emerged as a strategy used by European countries to advance their local economies through regional collaboration. This did not only enable them to establish and uphold relationships across regional borders but also strengthened the administrative capabilities of their municipalities (Matsiliza, Nzewi \& Zwane 2018). In developing countries where municipalities have inadequate financial capacity and limited autonomy to provide quality and cost effective services to the public, city twinning can offer them a platform to improve democratisation and decentralisation of the current service delivery status as it has in developed countries (Ijeoma \& Nzewi 2016). As noted by Wood (2015), local authorities should, from time to time, explore new ideas beyond their limits to address urgent needs. Therefore, this article suggests that the Zimbabwean local authorities can improve service delivery and benefit immensely in the areas of city development, urban competitiveness and human resource development through twinning arrangements. The study therefore unpacks the utility and impact of twinning arrangements on service delivery between eThekwini Municipality and Bulawayo City Council (BCC).

\section{Background of the study}

Local authorities in Zimbabwe have been characterised by a continuous deterioration in the area of service delivery because of over two decades of economic turndown being experienced in the country (Dube 2019). As decentralised entities, they are tasked with the provision of basic services and the maintenance of critical public infrastructure to deliver them. However, they lack the capacity to cope with the increasing demands for efficient service provision and maintain the 
infrastructure to deliver them. In addition, the perpetual failure by Zimbabwean municipalities to obtain clean audits as reviewed by the Auditor General's reports is further evidence of the bad state these municipalities are in (Chilunjika, Mutema \& Dube 2020). This continued failure to obtain clean audits is also destroying the image and stakeholders' perceptions towards the municipalities (Dube 2019). To recover from these challenges, the government has since taken a policy position to adopt public sector reforms that are informed by the New Public Management (NPM) approach.

New Public Management has opened novel opportunities for greater efficiency and effectiveness in local authorities in Zimbabwe. This approach offers numerous strategies to improve service delivery which include, city twinning, publicprivate partnerships (PPP), shared services, outsourcing and privatisation. These strategies enable local governments to collaborate with other local, regional and international municipalities to share experiences, expertise and information in the pursuit of efficient and quality service provision (De Villiers 2005, Haffek 2003). Similarly, Molepo (2018) noted that for the past decade, NPM has been the main driver for the twinning arrangements to rescue the ailing local governments by amalgamating their reform strategies with those from developed local authorities within their regions and abroad. The government of Zimbabwe has since opened its doors to numerous developed towns from all over the world as twinning partners in a bid to transform its municipalities.

To date, numerous local authorities in Zimbabwe are signatories to many regional and international twinning arrangements as part of their development agendas. This include Harare partnering with Munich in Germany, Cairo (Egypt) and Cheonan city (South Korea), whilst Beitbridge town partnering with Musina in South Africa and Bulawayo town with Polokwane South Africa, Francistown in Botswana, Aberdeen in Scotland and eThekwini in South Africa. All these twinning arrangements have been aimed at improving service provision, town governance, municipal administration, urban planning, architecture and town management.

Nevertheless, when adopting twinning partnerships a number of questions arise. Some of the key questions are as follows: What is the rationale for twinning partnerships and what value do they bring with them? (Jones \& Blunt 1999). A number of scholars have shared experiences and lessons to be learnt on twinning arrangements and their implications on local government operations. It should, however, be noted that there is a paucity of literature on studies focusing on city twinning in Zimbabwe. For instance, a search on Google Scholar of articles pertaining to city twinning in Zimbabwe from 2015 to 2021 returned only 31 articles. Hence, this article seeks to contribute to the extensive exploration of twinning partnerships as strategies that enhance service delivery in Zimbabwe's local authorities using the case study of Bulawayo and eThekwini. This article is organised as follows: the first section examines the theoretical aspects of city twinning, the second section highlights empirical findings on the improvements achieved in the area of service delivery in developing countries, and the third section discusses the Bulawayo and eThekwini scenario.

\section{Research objectives}

The study focuses on city twinning and its impact on service delivery with specific reference to Bulawayo-eThekwini municipalities. The main objectives that the study seeks to achieve are the following:

- To review literature on the concept of city twinning.

- To assess the impact of city twinning partnerships on service delivery at BCC.

- To explore how the Bulawayo-eThekwini twinning arrangement has addressed service delivery challenges of BCC.

\section{Literature review Unpacking the concept of city twinning}

Numerous studies have been published on city twinning because of the potential it has in supporting the developmental incentives of municipalities around the globe. De Villiers (2005) defined city twinning as the long term strategic union between various cities in which their municipalities play a key role. City twinning therefore enables local governments to exchange knowledge and innovation in the field of town and municipality management. It is important to note that twinning takes place in a complex stakeholder context; and these stakeholders include the partners, donors, employees and the citizens who are intended to benefit from improved service delivery, arts and culture exchanges and social inclusion and solidarity (APEC 2008). It is crucial that the voices and interests of these stakeholders be taken into account throughout the partnership as it ensures their support towards the partnership. Additionally, it must be noted that, city twinning arrangements do not occur in isolation. The political, economic and organisational contexts and policies of both the partners are important for effective twinning to take place.

On the other hand, Furmakiewic (2020) defined city twinning as a development initiative in which developing communities learn from the developed ones. This suggests that developing communities are dependent on the advanced economies as also exhibited through numerous North-South partnerships. However, Bandauko and Bobo (2018) are of a different view regarding this concept. To them city twinning is move away from the traditional donor-receipt model to a more collaborative and mutual type of collaboration where two parties bring together their resources to attain shared benefits. This is in line with the NPM principles that promote efforts for partnerships and collaborations in government operations to enhance strengths and resolve weaknesses. As a result, many governments in developing countries have been moving towards collaboration and other forms of cooperation to address service delivery challenges. Today the concept of city twinning is showing great potential in synchronising international, regional and local efforts towards achieving sustainable urban development in low income countries. 


\section{The nature of twinning}

According to DeVilliers, Coning and Smit (2007), the concept of twinning is not static and has evolved notably since its origin. The authors further identified three different but interlinking and overlapping phases of twinning which are as follows:

1. The associate phase: twinning centred on cultural and friendship exchange.

2. The reciprocative phase: twinning centred on educational and people exchange.

3. The commercial exchange phase: twinning centred on economic development.

Recent studies suggest that twinning in the 21st century is more based on the commercial exchange phase as a response towards globalisation, regionalism, and local socio-economic factors that are driven by new markets, increased competition and a novel complexity to global supply chain (Molepo 2018). The same can be said for the Bulawayo-eThekwini twinning arrangement which was established to foster sustainable development for BCC through technical and information exchanges. In addition, twinning centred on economic development presents a more diverse landscape for international cooperation that brings together new partners and new approaches that lead to sustainable development. Furthermore, these twinning partnerships can also improve the economies of the sister cities as witnessed through infrastructure development, improved town and environmental management, and in some cases job creation. For example, the Melbourne (Australia) and Tianjin (China) twinning partnership has enabled the two municipalities to work together in designing green energy technology so as to protect the environment, whilst at the same time creating jobs for their citizens (Bandauko \& Bobo 2018). Although it has been observed that the aspirations to establish twinning relationships are diverse at different junctures of international relations (Joenniemi \& Janczak 2017); the underlying fact is that the parties involved are joining their resources to realise mutual benefits.

The concept of twinning can also be discussed in the context of geographic orientation, for example North-North partnerships, North-South partnerships and South-South partnerships (Bandauko \& Bobo 2018). According to Stephen (2008) North-North partnerships are the most common city twinning arrangements in the world which mainly focus on promoting social and cultural ties within the European region through the exchange of people and goods of all kinds. These links are based upon sharing equal resources and on the principle of reciprocity aimed at unifying people across national boundaries to strengthen peace and build a united Europe. Whilst the central focus of most North-North partnerships may be socially rooted, many of these links also focus on economic development through technical cooperation activities (United Towns Organisation [UTO] 2001). Today many of these partnerships are aimed at improving town management in the areas of energy, transport, infrastructure and environment. For example, Birmingham (United Kingdom [UK]) has established several successful twinning partnerships with other European cities. Examples of successful projects include a joint project with Leipzig (Germany) on canal regeneration and a joint scheme with Lyon (France) on the refurbishment of public buildings.

North-South partnerships are often instigated from the North and at times on the basis of previous colonial ties (UTO 2001). There are many examples of North-South linkages between towns in nearly all European nations and countries from the South. These are aimed at fostering development and capacity building. In Zimbabwe, the Harare-Munich (Germany), Bulawayo-Aberdeen (Scotland) and MutarePortland (United States of America [US]) are good examples of this. These links have for a long time been seen as a means for humanitarian aid rather than a partnership or technical collaboration. However, recent studies point out that some which started in this way have over time evolved through the realisation that such partnerships can bring two-way benefits from shared services and management (Matsiliza et al. 2018).

In recent years, interests have grown significantly for SouthSouth partnerships. These twinning partnerships are between countries in the South who seek to learn from each other at a less costly rate as they will be geographically closer when compared to North-South partnerships. Examples for this type of partnerships include: the Musina-Beitbridge partnership and the Bulawayo-eThekwini twinning. They stem from the idea that southern communities share similar social, economic and political problems, and as a result can learn from solutions developed by one another (Bandauko \& Bobo 2018). Similar to North-North partnerships, these have the potential to enhance regional solidarity and development. Nevertheless, the number of such twinning relationships still remain limited (Sister Cities International 2020; Bandauko \& Bobo 2018). This is because twinning partnerships of this nature are mostly weakened by resource constraints (financial, human resources and infrastructure) faced by many of these southern countries (Joenniemi \& Janczak 2017; Johnson \& Wilson 2006; UTO 2001). As a result, there are concerns around the long-term sustainability of the achievements witnessed during such twinning arrangements. Whilst there is not much experience of town twinning and collaboration on South-South partnerships (Molepo 2018), the study believes that these collaborations have the potential to add value to community development through regional economic development and job creation.

\section{Improving local government capacity through twinning strategies}

\section{Institutional capacity building}

According to APEC (2008) institutional capacity building for public institutions seeks to improve their ability to deliver services effectively and efficiently on a continuous basis. In the context of twinning, institutional building suggests copying or modelling, where the less developed municipality learns from the developed one which serves as the model (Jones \& Blunt 1999). What is implied here is that 
municipalities are not self-reliant and as a result they want to learn from the best practices of other municipalities in order to improve their operations. Consistent with this view are Kolb et al.'s Experimental Learning theory and Revans' Action Learning theory which suggest that learning is underpinned on experience learnt from others (Kolb, Rubin \& McIntyre 1971; Revans 1980). Both theories emphasise that institutional capacity building only takes place when employees in an organisation reflect on the experiences learnt from others and experiments with new ideas and behaviours exposed to them during the interaction process.

For local authorities to benefit from twinning, they must identify key areas where the partnership is expected to assist in organisational development and learn from each other. These areas may include operational approaches and cultures around quality management. A study by Matsiliza et al. (2018), for instance, revealed that municipalities in South Africa are benefiting from their twinning partners through Quality Circles (QC), which is a strategy used in the private sector to inculcate a culture of quality services provision, whereby twinning partners audit each other whilst learning to improve service delivery in the process. However, some scholars are critical of the effectiveness of private sector strategies in the public organisations. This particular approach, for example, requires strong commitment and support from the management and employees to keep the circle functional which usually lacks in public managers and employees when it comes to reforms and change (Matsiliza et al. 2018). Additionally, adopting QC should be done with great caution as some employees will not get admitted into circles because they are aiming at transforming the personnel's attitudes to perform. In this regard, adopting private sector strategies in the public sector requires tailored approaches considering the complexities of their application and use. However, it is beneficial to the public that municipal employees be oriented towards quality management and other private sector strategies as they lead to the provision of value for money services.

\section{Service delivery and twinning arrangements}

Local governments are agents used by the state to provide basic goods and services (health, education, daily provision of water and refuse collection) to the public to ensure a certain degree of well-being (Makanyeza, Kwandayi \& Ikobe 2013). These agents are expected to be developmental and able to deliver services that have significant impacts on the quality of the citizens' lives. In providing these services, local governments create opportunities for citizens and local companies to make desired changes that would not have been possible without the municipality's engagement (Eigeman 2007). These desired changes are achieved through the municipality's networks, resources, techniques and guidance. However, the municipalities in developing countries like Zimbabwe have limited autonomy and less financial capacity which creates a limitation to achieve these desired changes. Consequently, engaging in city twinning partnerships thus gives local authorities in developing countries the opportunity to work collaboratively with regional and international cities and to share experience and information in numerous municipal management areas, which ultimately improves service delivery (De Villiers 2005).

\section{Twinning arrangements and service delivery- related improvements in selected areas}

The main goal of twinning is to create long term relationships for mutual benefit (Franco \& Marmelo 2014). However for struggling communities in the South, concrete improvements in the area of service provision have come about through their partnerships with the North and fellow South counterparts. There are numerous benefits of twinning which have been cited by different scholars in the area of service delivery, and these include improved health, education, sanitation and waste management services (Bandauko \& Bobo 2018; De Villers 2005; DeVilliers, Coning \& Smit 2007; Sibanda 2017). Table 1 gives a summary of positive improvements that have been achieved in selected developing countries in the area of service delivery.

Closely related to service delivery is the concept of good governance. The spread of decentralisation and increased democratisation is enabling local governments in developing countries to take more responsibility for improving their performance and providing public services regardless of having limited resources (Molepo 2018). This is because decentralising power to local governments stimulates them to become entrepreneurial in order to achieve local economic development. Zinyama and Nhema (2015) noted that by partnering with other cities and professional associations transparency, accountability and sound financial management systems are inculcated in the operations of local authorities and this has a positive impact on service delivery.

TABLE 1: Examples of improvements achieved in service delivery in developing countries.

\begin{tabular}{|c|c|}
\hline Area & Example \\
\hline Literacy and Education & $\begin{array}{l}\text { Twinning links between South Africa and Sweden } \\
\text { municipalities have contributed to the enhancement of } \\
\text { formal and informal education and lifelong learning for } \\
\text { many South Africans in Buffalo City, Da Aar, Port } \\
\text { Shepstone and Port Elizabeth towns through educational, } \\
\text { training and cultural exchanges which are funded by SIDA } \\
\text { (Swedish International Development Agency), the } \\
\text { Swedish Association for local authorities and the Olaf } \\
\text { Palme International Centre (De Villiers 2005). }\end{array}$ \\
\hline Health & $\begin{array}{l}\text { The Los Angeles municipality (US)-Lusaka City Council } \\
\text { (Zambia) partnership formed in } 1967 \text { has incorporated } \\
\text { health issues in their development agenda. To date, projects } \\
\text { implemented through this link have successfully assisted } \\
\text { with a broad range of health issues including nutrition, } \\
\text { sexual reproductive health, HIV and AIDS, pharmaceutical } \\
\text { supplies and minor health equipment (A report by the Los } \\
\text { Angeles-Lusaka Sister City Committee 2012). }\end{array}$ \\
\hline Waste management & $\begin{array}{l}\text { Waste management projects under the Munich } \\
\text { municipality (Germany)-Harare City Council (Zimbabwe) } \\
\text { twinning arrangement have reported fairly positive } \\
\text { results. Harare has benefited in terms of gaining expert } \\
\text { knowledge on solid waste management and by receiving } \\
\text { refuse collection vehicles for service delivery (Bandauko } \\
\& \text { Bobo 2018). }\end{array}$ \\
\hline Provision of water & $\begin{array}{l}\text { In } 2005 \text { Beitbridge City Council (Zimbabwe) and Musina } \\
\text { Municipality (South Africa) entered into a twinning } \\
\text { arrangement which was aimed at achieving effective and } \\
\text { efficient management of the Limpopo river which serves } \\
\text { as a source for domestic, commercial and industrial use } \\
\text { for two local governments. This twinning arrangement } \\
\text { has brought much change for the betterment of the two } \\
\text { municipalities in terms of water provision and alleviation } \\
\text { of pollution (Bandauko \& Bobo 2018). }\end{array}$ \\
\hline
\end{tabular}




\section{Methods and material}

The BCC and eThekwini Municipality were used as a case study for the collection of primary data although much emphasis is placed on BCC and how it has been impacted upon by this twinning arrangement with eThekwini Municipality. An exploratory case study research design was purposely chosen and used as it allows the exploration of a phenomenon within its original setting using multiple data sources. This enabled the issue under study to be explored through a variety of lenses thus permitting multiple facets of the phenomenon to be revealed and understood (Baxter \& Jack 2008). The main method of data collection was written documents, observations and in-depth interviews with individuals from the BCC, the business community and Bulawayo residents to get their insights on the subject of twinning and service delivery.

A total of 18 participants from the BCC were purposively selected for this research based on their availability and knowledge to provide data that is detailed and relevant to the study. The participants were only chosen from Bulawayo as the study sought to assess the impact of twinning partnerships on the service delivery at BCC. The researchers asked questions orally using interview guides and recorded the answers of the respondents. Interviews with the community members were conducted in Ndebele and Shona which are the most popular languages in Bulawayo and then translated into English. A search strategy was carried out for studies related to city twinning, municipal cooperation, collaborative management and service delivery using online libraries in Google Scholar, Scopus, ScienceDirect and Emerald. Searches were also conducted on the Internet for grey literature such as published studies and theses from the fields of public finance, public management, public policy and urban studies. Additionally, the authors also used unpublished documentation relating to the case study including project documents and progress reports. A total of 33 papers were reviewed, analysed and reused to produce new knowledge. Qualitative document analysis was preferred for this study because of its applicability to existing studies to produce additional information (Auriacombe 2017). Having noted that twinning is a crucial strategy to enhance service delivery in local authorities, this study intends to give an answer to the following question: Can local governments in Zimbabwe successfully collaborate with other regional and international municipalities to gain knowledge and expertise with the intention to improve service delivery?

The researchers also conducted direct observations in Bulawayo's residential areas, and council offices' observable systems and activities to assess the prevailing state of service delivery, infrastructure and operational processes. As a way of ascertaining validity, the researchers exercised reflexivity all the time making sure that preceding experiences and values did not affect the reporting of findings. To enhance internal validity, the researchers also made use of the audit trail which helped in the keeping of detailed and accurate records of everything the researchers did and of the data collected. Meticulous documentation of sampling format, tools development and data collection was also conducted for reliability. This is because documentation brings reliability as it ensures that if anyone wants to repeat this study they can be guided accordingly and get the same results (Yin 2009 cited in Chilunjika 2018). All qualitative data gathered was then analysed using textual and content analysis.

\section{Results}

Bulawayo is the second largest city in Zimbabwe with a population of about 1.5 million people (Sibanda 2017). At one time, Bulawayo was regarded as the epicentre of industries in Zimbabwe, having industries producing cars and car products, textiles, food and building materials. However, over the years the city's economy has been crippled because of the closure of these industries and the economic instability experienced in the country over the past two decades (Sibanda 2017). This has seen a major drop in service delivery and economic development in the town. In a bid to improve service delivery, urban governance, municipal management, urban planning and management the town has engaged in partnerships with six cities to date. These are with Aberdeen-Scotland, Polokwane-South Africa, Katima Mulilo-Namibia, Francistown-Botswana, Livingstone-Zambia and DurbanSouth Africa. Out of the twinning arrangements which the City of Bulawayo has had, its partnership with the City of eThekwini is the one that appears to be vibrant. This is because this partnership has produced more tangible capacity gains for the city council in water and sewer management, information technology systems and improved municipality management than any other twinning partnership as will be discussed in subsequent paragraphs.

\section{Challenges faced by the Bulawayo City Council in the provision of public services}

Like any other municipality in Zimbabwe, the BCC has been experiencing chronic deficits in the provision of basic services such as sanitation, waste management, health, and water provision (Sibanda 2017). Both officials from the BCC and members of the public noted that these challenges have been instigated by a combination of interwoven factors which include corruption and mismanagement, rapid population growth, inadequate financial and human resources, inadequate water bodies, political interference, lack of political will and poor participatory local governance structures. From the interviews, the general impression from the residents was that they were not receiving value for their hard earned money and have resorted to not paying their service fees and rates. As viewed by the residents, there is gross corruption during the tendering processes and mismanagement of funds are the major factors contributing to the poor service delivery in Bulawayo. Resident $C$ had the following to say: 
'Mina ngibona ingathi kulesitsotsi emaTendeni laphana, those people who are closer to Town Clerk yibo abathola amaTender, awanikwa ngokuthi uyakwanisa ukwenza umsebenzi wakhona, hayi!! Its obvious abo Town Clerk badinga abantu babo vele besebesi vala ngokwenza amaTender for umthetho nje otherwise...vele amaTender aphiwa ngokwazana ...' (I think that there is no transparency in how Tenders are awarded. Those closer to the Town Clerk are favoured. There is no meritocracy, opening of tenders is only done as a formality, otherwise the winner would be known already).

In addition, Resident A noted that:

'Council Staff squander our money and buy themselves the latest Jeeps and Fortuners when we have potholes and they cut our water. Right now street lights are not functioning; crime is taking place in some high density residential areas because tower lights are off. Sewage water is everywhere and every day we worry that there will be a Cholera outbreak. Where do they put our money?'

To the residents it is callous of the management to get the new luxurious vehicles as well as other hefty benefits, when the municipality is failing to deliver basic services to taxpayers. It was indeed observed that some top-of-the-range vehicles were parked on the parking lots of the top council officials at BCC. On top of that, public procurement as a backbone of effective service delivery should be safeguarded from corruption, unfair procurement practices and political interference as it often involves large funds of public resources (Chigundu 2014). However, from the residents' sentiments such practices remain prevalent at BCC, and there is no will on the management's part to address them because they benefit from the system.

The researchers also observed heaps of uncollected garbage in Bulawayo Central Business District (CBD) and in many residential areas such as Makokoba, Magwegwe and Lobengula. To make matters worse, garbage bins and public refuse collection points are left exposed to the sun and rain which results in land and air pollution. These dumping sites become breeding grounds for flies, mosquitoes and rats which pose serious health threats to the people of Bulawayo. A review of the council's documents also revealed acute shortages of refuse equipment. At the time of this study, the local authority had one operational front end loader, one dozer and two tipper trucks which had to service over 13 residential areas. With regard to sewerage systems, the town is overwhelmed with collapsed sewers because of dilapidating infrastructure, thereby limiting sewer drainage capacity.

The management, however, blamed poor service provision to the economic environment in the country and legislative frameworks which govern their operations. This is in line with Chilunjika et al. (2013) who stipulated that the local government minister has too much influence in the decisions made by municipalities. They further stated that before municipalities implement their budgets, they must seek the approval of their tariffs and revenue from the minister who has the veto power to reject a budget where he 'feels' the tariffs are beyond the affordability of the public or where he 'feels' the expenditure is not reasonable. In the end, local authorities are forced to undercharge services, and operate on inadequate budgets which lead to poor quality and limited expansion of services.

The low influx of water service charges has also resulted in poor water provision in Bulawayo and this is the reason why the residents go for longer periods without water. A Bulawayo Progressive Residents' Association bulletin of 2009-2013 revealed that some areas such as Gwabalanda, Entumbane, Nketa and Mzilikazi could go up to 15 days per month without water. In an interview with the chairperson of the Bulawayo United Residents, he raised concern over the rate of water rationing and water disconnection in the city. He highlighted that by disconnecting and over rationing water, the municipality was demonstrating a lack of empathy to the plight of its residents. When asked to comment on this, an official from the Town Clerk's office articulated that water rationing was inevitable because of water levels in most Bulawayo dams which could not sustain the growing population. He further stated that the municipality was also struggling to secure adequate funds to operate and maintain water systems and had resorted to disconnecting water on all residents who were not paying their rates. When asked about the quality of water provided by the municipality, the residents and council officers had different views. An official from the Water Works department expressed that the council always strives to provide safe water to its residents. However, some residents indicated that some days the water they receive is usually muddy brown in colour and with particles.

In summary, the above factors have succeeded in locking the BCC into a never-ending cycle of poor service provision. A vicious cycle characterised by non-payment of service fees and low charges, limited resources, financial indiscipline and corruption, which in turn results in the erosion of community confidence and low willingness to pay for services.

\section{The eThekwini-Bulawayo twinning partnership: A brief history}

The twinning partnership between eThekwini and Bulawayo was formed in 2002. The similarities between the two towns in terms of historical origins and culture facilitated the twinning in a quest to share ideas, innovation and experiences for economic and social gains (Camagu 2017). These similarities can be understood from the close connection of the Zulu and Ndebele cultures and the common history that the two cities share dating back to the Shaka and Mzilikazi reign. Activities within this twinning partnership fall into three categories and these are information exchanges, technical exchanges and collaborations on specific initiatives that is water and sanitation.

As a South-South linkage, twinning between these two cities is financed on a shared basis with the towns funding trips of their own staff and accommodation for visitors (City of Bulawayo 2012). Since 2002, twinning programme delegations (municipal staff, business people, community members) 
from the two towns frequently share and exchange knowledge, ideas and local traditions under various domains which range from culture, business, town management, water management, sanitation and health. Information and experiences shared under these spheres are then used to stimulate socio-economic development projects mainly in Bulawayo.

In 2009, under the framework of the twinning partnership, the BCC Director of Engineering Services approached eThekwini Water Sanitation (EWS) for technical assistance on the town's water crisis which was characterised by a precarious drinking water system and ageing wastewater infrastructure. The EWS is known for being the first to successfully introduce initiatives such as the use of grey water for urban agriculture, free basic water, urine diversion toilets, condominium sewerage, flow limiters and a customer water debt repayment policy to South Africa (Camagu 2017). For a municipality like BCC which lacked the needed resources, expertise and policies to fix its service delivery crisis, eThekwini technical expertise on water supply, sanitation and municipality management would prove to be indispensable to the BCC. To address these challenges, the two towns signed a Memorandum of Understanding which gave birth to the Bulawayo Water and Sanitation Emergency Response (BOWSER) Project in April 2010. The project design also included a number of partners such as AusAID, Dabane Trust (a Bulawayo based NGO) and World Vision who were mainly responsible for financial assistance. This project has become the main highlight of the twinning arrangement between the two towns.

\section{Service delivery under the eThekwini and Bulawayo partnership from 2009 to 2014}

The period from 2009 to 2014 saw a significant improvement in terms of service delivery at the BCC mainly as a result of the BOWSER project and the technical expertise that the council received from eThekwini. Activities done under the BOWSER project were implemented in two phases. Phase one was centred on sanitation, water and critical infrastructure rehabilitation and participatory health hygiene. Phase two was focused on information technologies upgrades, strengthening council institutional capacity, improving revenue collection, responsiveness to emergencies and consolidating the gains made during the implementation of phase one.

Notable achievements of phase one included the mapping of water and sewer networks using Geographic Information System (GIS) to monitor them in real time. This did not only reduce water loss but also reduced the vulnerability of Bulawayo residents to waterborne and water washed diseases through improved water supply and sewerage systems (Bulawayo Progressive Residents' Association bulletin 200912). There was a $40 \%$ drop of diarrhoeal cases reported at BCC health centres during the BOWSER project period; notably this drop also included children under the age of 10 who had been hard hit during the 2008 cholera outbreak in Zimbabwe (BOWSER Progress Report 2013). Figure 1 shows improved water supply outcomes from the BOWSER project between the period October 2011 to November 2012.

Figure 1 shows a strong upward trend in improved water supply in Bulawayo soon after the commencement of the BOWSER project in June 2010. The trend was sustained throughout 2011 to December 2012 as the water supply systems were gradually refurbished. By November 2012 about 200000 households had water connections installed, an indication that the project was significantly resolving the water crisis in Bulawayo (BOWSER Progress Report 2013). Technical expertise from eThekwini saw the development of service level standards which would guide the maintenance of water and sewer systems and these are still functional to date. Additionally a team of IT experts from eThekwini also visited Bulawayo to offer on-the-job training on the use of GIS to Bulawayo water works employees.

Project Participatory Health and Hygiene Education (PHHE) was also launched through the eThekwini-Bulawayo twinning. The focal messages of the PHHE project were on educating the community to act responsibly towards themselves, the community and the importance of paying their bills. Training manuals and materials for posters, billboards and pamphlets were provided by eThekwini and adopted from the Durban context for Bulawayo. Selected members of the public and council officials were trained and equipped to carry out education campaigns in schools, market places and churches. Roadshows with popular artists were also conducted and bill boards were erected on main roads to ensure that there was wide coverage on health and hygiene matters. As a result of PHHE, there was an increase in health and environmental awareness which saw a reduction in pollution, unhealthy practices and a steady upsurge in bill payment by the residents to fund service delivery.

The key results achieved from phase one are highlighted below from the BOWSER Progress Report (2013):

1. Rehabilitated nine sewerage pumping stations.

2. Cleaned over $250 \mathrm{~km}$ of sewerage pipes and de-choked sand traps resulting in a decrease of sewer blockage complaints between February 2010 and July 2010 from 41 to 14.

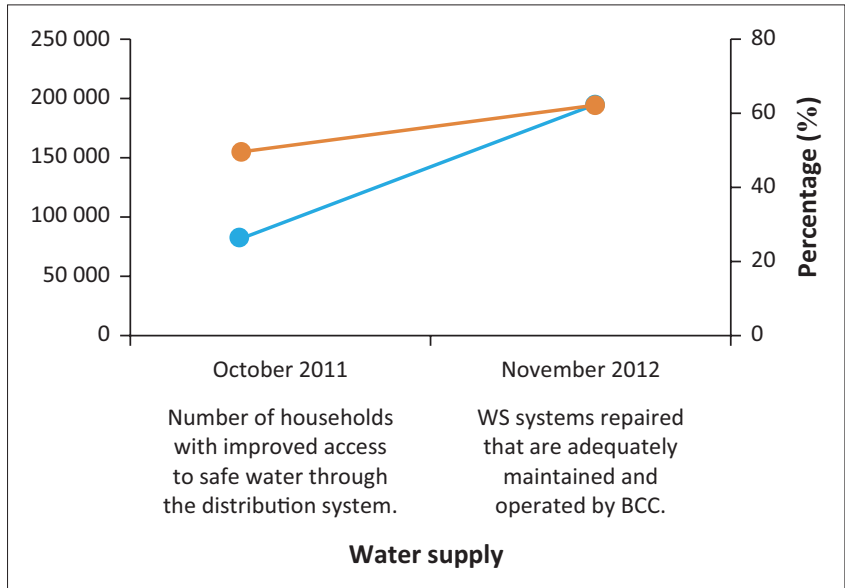

Source: Water Operators' Partnership in Africa Case study 3 (2014) FIGURE 1: Improved water supply. 
3. Repaired over 1200 water leaks, significantly reducing water losses.

Phase two of the BOWSER Project saw the introduction of an Information Communication Technology (ICT) project to enhance financial sustainability at BCC through expert knowledge from EWS. The project was targeted at improving service delivery and addressing the municipality's ineffective billing and revenue collection system. It was a development which fostered accountability, transparency and strong internal accounting systems at BCC. Council financial records between 2011 and 2012 showed a positive trend of over 65\% from $16 \%$ in $2009-10$. The municipality is now able to reinvest part of the increased revenue into mainstream service delivery. In addition to this, the municipality adopted more transparent procurement procedures to reduce corruption and improve transparency in the procurement process. This saw the creation of a council website where the public can access information and advertisements on tenders. However, despite such efforts corruption during the procurement process remains rampant in Zimbabwe's local authorities (Dube 2019).

Technical expertise from eThekwini also facilitated the establishment of a call centre with appropriate security, software and an accurate customer information base for BCC in 2011. The call centre was a huge commitment towards better service delivery through increased customer care, convenience, responsiveness and public sector efficiency. The then Mayor of Bulawayo, Thaba Moyo, had the following to say:

'Bulawayo is honoured to be the first municipality in Zimbabwe to introduce a call centre to improve communication with its residents ... this is just the beginning in our quest to increase service delivery and preserve the spirit of Ubuntu in our people'.

In line with the call centre as a means of improving service delivery through increased customer care, most Bulawayo residents agreed that there was significant overall improvement in the council's responsiveness to service faults which they reported. One prerequisite for quality customer care is convenience. All the residents who were interviewed highlighted that the $24 \mathrm{~h}$ call centre gave them convenience as they no longer had to physically visit council offices every time they have queries or to report faults. As call centres have the prospect to advance service delivery, municipalities are progressively becoming interested in using them as an e-government tool. Not only can call centres provide opportunities to deliver quality services to citizens but are also vital in engaging them in policy making and implementation discussions (As-Saber \& Hossain 2010). From the literature reviewed, citizen engagement and involvement are important factors in improved service delivery as they are the ones directly affected by the decisions made by the municipality (Eigeman 2007; Makanyeza et al. 2013; Whitaker 1980). This is because citizens have better ideas of the kind of services they need than public officials. Most importantly, citizens can be a source of ideas and inspiration for social innovations which have been found to be vital in the decision making process (Whitaker 1980).
Nonetheless, setting up a call centre is not enough in resource constrained settings like Zimbabwe. There is a need to ensure that public organisations using them have an adequate number of qualified people to operate them. The main purpose of such technologies is to increase responsiveness and efficiency. Failure to attend to customers on time and with speed make them redundant in the public sector.

Twinning between Bulawayo and eThekwini is not only limited to economic development projects but also to social issues which include culture, arts and sports. Shaw (2002) stated that twinning arrangements should extend beyond economics and politics to social and recreational aspects of the society. Similarly, Makanyeza et al. (2013) noted that local authorities have a duty to provide social and recreational services to the public. In line with this, the National Gallery in Bulawayo and the Durban Art Gallery signed a contract to promote each other's talent in their respective towns. This partnership has also opened opportunities for young musicians and actors in Bulawayo thus creating employment for the youths including Charles Nkomo who has showcased his art at the KwaZulu-Natal Society of Arts Gallery (Bulawayo Council Records 2010). Council records at BCC also revealed attendance and participation of Bulawayo youths at the 2009 One Nation tournament that took place in Durban. There has however no sporting event that took place after this because of economic challenges faced by the BCC.

\section{Discussion}

Development and service delivery are core responsibilities of local authorities because it is the local authority which governs most closely to the community (Tamrakar 2010). However, because of numerous challenges faced by local authorities in low and middle income countries, service delivery and development remain difficult tasks to achieve. To them, city twinning has become an essential tool to improve service delivery, promote sustainable city development and good governance. The twinning arrangement between the BCC and eThekwini has produced positive results with the BOWSER project being the major tangible fruit of the partnership. Twinning between the two municipalities is linked to technical and information exchanges which Bulawayo has benefited from in terms of best practices in water supply and sewerage systems, customer care, arts and financial sustainability. As a result of such improvements, $B C C$ received the Zimbabwean Best Performing Local Authority Award in 2012.

As suggested earlier, South-South partnerships are aimed at facilitating southern communities to learn from each other as they are geographically closer, share similar social, economic and political problems (Buursink 2001). The BOWSER and the call centre projects are proof that such partnerships can be a success. The EWS is geographically close to Bulawayo and it shares to some extent the BCC's operating environment. In selected cases, some expertise was practically directly transferable, for instance the call centre design and the Hygiene Education campaign supplies. Moreover, because of 
its geographical proximity, EWS was well placed to oversee and monitor the progress of the projects thus their success.

Despite the notable accomplishments of the BCC and eThekwini linkage in service delivery from 2009 to 2014, the sustainability of the achievements of this partnership were however constantly threatened by the economic and legal environment in Zimbabwe. This study observed that many achievements of twinning partnerships in Zimbabwe are not sustainable because of lack of policy consistency, currency changes, the dearth of financial resources, and rampant corruption and investor perceptions of rife political risk. Weak legal and financial frameworks thus hinder city twinning partnerships from realising their full fruition.

\section{Conclusion and recommendations}

This article sought to highlight that local governments in resource constrained settings like Zimbabwe can adopt city twinning to strengthen their operations and contribute to the ongoing debates on strategies for improving service provision in municipalities. Although North-South cooperation is more ideal for fostering development, the study suggested that developing cities can benefit immensely from each other through South-South linkages as exhibited by the BCC and eThekwini twinning. However, sufficient attention should be given to ensure that such partnerships are built explicitly on defined goals, enabling policy and institutional environment, broad active community involvement, communication and binding contractual obligations. In addition, key aspects of twinning arrangements such as funding, nature of twinning and selection of operational staff are clarified and established at the beginning of the project rather than assumed as it can threaten the relationship between the two partners.

\section{Acknowledgements}

We would like to acknowledge all the participants who provided us with the data in order for the research to be successful.

\section{Competing interests}

The authors declare that no competing interests exist.

\section{Authors' contributions}

Both the authors contributed equally to this research, in terms of conceptualisation, methodology, data collection and data analysis, writing, review and editing.

\section{Funding information}

This research received no specific grant from any funding agency in the public, commercial or not-for-profit sectors.

\section{Data availability}

Data sharing is not applicable to this article as no new data were created or analysed in this study.

\section{Disclaimer}

The views and opinions expressed in this article are those of the authors and do not necessarily reflect the official policy or position of any affiliated agency of the authors.

\section{References}

APEC, 2008, APEC Twinning Implementation essentials, viewed 02 January 2021, from @ wwwapec.org.

As-Saber, S.N. \& Hossain, K.M., 2008, 'Call centres and their role in e-governance: A developing country perspective', Community Informatics 4(3), 1-21.

Auriacombe, C.J., 2017, Research methodology of public management and governance and research proposal. UJ Internal Prescribed Handbook, University of Johannesburg, Johannesburg.

Bandauko, E. \& Bobo, T., 2018, City partnerships and implications for local government operations: A case study of Harare (Zimbabwe) and Munich (Germany), Twinning Arrangement IGI Global, Hershey, Pennsylvania. https://doi.org/104018/978-15225-4165-3.ch003

Baxter, R.E. \& Jack, C., 2008, The art of case study research, Sage, Thousand Oaks, CA.

BOWSER Progress Report, 2013, Water operators' partnership in Africa. Case study 3 Bulawayo and eThekwini, UNHSP, viewed 29 January 2021, from www. unhabitat.org.

Bulawayo Council Records, 2012, Bulawayo City Council Archives. Bulawayo City Council Press, Bulawayo.

Bulawayo Progressive Resident's Association bulletin 2009-12.

Bulawayo City Council Annual Reports from 2009 to 2014.

Buursink, J., 2001, 'The Binational reality of border-crossing cities', GeoJournal 54(1), 7-19. https://doi.org/10.1023/A:1021180329607

Camagu, A., 2017, 'Analysis of the effectiveness of international partnership agreements in local municipalities in South Africa: Case of eThekwini municipality', Unpublished Master's degree dissertation, viewed 24 February 2021, from https://researchspace ukzn.ac.za/handle/1041316433.

Chigundu, D., 2014, 'Public procurement in Zimbabwe issues and challenges', Journal of Governance and Regulation 3(4), 21-26. https://doi.org/10.22495/ jgr-v3-14p2

Chilunjika, A., 2018, 'The performance of automated toll revenue mobilisation systems in Zimbabwe', Unpublished Doctoral thesis, University of Johannesburg, Johannesburg.

Chilunjika, A. Mutema, E.P. \& Dube, B. 2020, 'Impediments to effective Councilor Oversight at Nkayi Rural District, Zimbabwe', International Journal of Law and Public Policy 2(2), 56-64. https://doi.org/10.36079/lamintang. ijlapp-0202.137

City of Bulawayo, 2012, Water Operators' Partnerships in Africa, UN Habitat, Nairobi.

De Villiers, J.C., 2005, 'Strategic alliances between communities with special emphasis on the twinning of South African cities and towns with international partners', Unpublished doctoral dissertation, Graduate School of Business, University of Stellenbosch, Bellville Park Campus.

DeVilliers, J.C., Coning, T.J. \& Smit, E., 2007, 'Towards an understanding of the success factors in international twinning and Sister-City Relationships', South Africa Journal of Business Management 38(1), 1-10. https://doi.org/10.4102/sajbm. v38i1.573

Dube, C., 2019, Main bottlenecks at the local authorities level that pose challenges for growth and sustainability, Zimbabwe Economic Policy Analysis and Research Unit. Harare.

Eigeman, S., 2007, 'The service concept: The missing link in service design research?', Journal of Operations Management 20(3), 121-134. https://doi.org/10.1016/ S0272-6963(01)00090-0

Franco, M. \& Marmelo, E., 2014, 'Sister city relationships as a form of inter organizational cooperation: Exploratory case studies in the Portuguese context', Transylvanian Review of Administrative Science 41(E), 75-89. Corpus 1D 73670458.

Furmakiewic, Z., 2020, 'Town-Twinning as a factor generating international flows of goods and people-the example Poland', Belgian Journal of Geography 1-2, 145-162. https://doi.org/10.4000/belgeo.12466

Haffek, P., 2003, 'An introduction to decentralised cooperation: Definitions, origins and conceptual mapping', Public Administration and Development 23(3), 333-345. https://doi.org/10.1002/pad.286

ljeoma, E.O.C. \& Nzewi, O., 2016, 'Work Procedures Applications in Municipal Government: Perspectives from Local Government Employees in South Africa', Journal of Public Administration 51(1), 58-72.

Joenniemi, P. \& Janozak, P., 2017, 'Theorizing town twinning-towards a global perspective', Journal of Borderland Studies 32(4), 423-428. https://doi.org/10.10 80/08886555.2016.126783

Jones, M.L. \& Blunt, P., 1999, 'Twinning as a Method of Sustainable Institutional Capacity Building', Public Administration and Development 20(4), 319-325. 
Kolb, D., Rubin, I. \& McIntyre, H., 1971, Organisational psychology: An experiential approach, Prentice-Hall, Englewood Cliffs, NJ.

Los Angeles-Lusaka Sister City Committee Report 2012, viewed 14 February 2021 from http://sistercities.lacity.org.

Makanyeza, C., Kwandayi, H.P. \& Ikobe, B.N., 2013, 'Strategies to improve service delivery in local authorities', International Journal of Information Technology and Business Management 15(1), 1-11.

Matsiliza, N.S., Nzewi, O.I. \& Zwane, Z.M., 2018, Town twinning in local governments: Applying work procedures for municipal collaborations. Cultures, philosophies and Reforms, Public Administration for the Globalising world: A reflection on local, Regional and International Association of Southern African Schools and Departments of Public Administration and Management book series, vol. 1, pp. 17-39, AOSIS, Cape Town.

Molepo, J.N., 2018, 'Global town to town relations: An exploratory study of the city of Tshwane in South Africa', Journal of Business and Economics 12, 1034-1041. https://doi.org/10.15341/jbw (2155-7950)/12/09/2018/003

Johnson, H. \& Wilson, G., 2006, 'North-South/South-North partnership closing the mutuality gap', Public Administration and Development 26(1), 71-80. https://doi. org/101002/pad.396

Shaw, B.A., 2002, 'Sister-City Partnerships and Cultural Recreation: The Case of Japan', World Leisure Journal 44(2), 44-50.

Sibanda, P., 2017, 'Challenges of local authorities service delivery a case of Bulawayo City Council', Unpublished Master's dissertation, MSU library, viewed 15 February 2021, from http://hd/handle.net/11408/3014.
Sister Cities International, 2020, Sister Cities at the cutting edge of economic and community development, Washington, DC, viewed n.d., from http://www.sistercities.org.

Stephen, C., 2008, Joint Report on Inverness City Manager and Chairman, The City of Inverness Town Twinning Committee, viewed 27 May 2021, from http://www. highland.gov.uk/NR/rdonlyres/1C07A195-EF04-454D81B8-ADAEE15058FC/ ICC998'08.pdf.

Revans, R.W., 1980, Action learning, Blond and Briggs, London.

Tamrakar, R., 2010, Impact of citizen charter in service delivery: A cased of district administration office, Kathmanda. North South University Press, Bangladesh.

United Towns Organisation (UTO), 2001, City to city cooperation issues arising from experience, An Interim Report Prepared as a Contribution to Discussions on Decentralised Cooperation at the UTO Unity Congress, Nairobi, Kenya, June 25, 2001.

Whitaker, G.P., 1980, 'Coproduction: Citizen participation in service', Public Administration Review 40(3), 240-246. https://doi.org/10.2307/975377

Wood, A., 2015, 'The Politics of Policy Circulation: Unpacking the Relationship between South African and South American Cities in the Adoption of Bus Rapid Transit', Antipode 47(4), 1062-1079.

Yin, R., 2003, Case study research: Design and methods, Sage, Beverly Hills, CA.

Zinyama, T. \& Nhema, A.G., 2015, 'Public-private partnership: Critical review and lessons for Zimbabwe', Public Policy and Administration Research 5(6). 39-44. 